UMBERTO CASSIANO GARCIA SCRAMIM

\title{
DA EXPANSÃO DOS DANOS INDENIZÁVEIS E SUA CATEGORIZAÇÃO
}

\author{
Dissertação de Mestrado \\ Orientadora: Professora Titular Silmara Juny de Abreu Chinellato
}

UNIVERSIDADE DE SÃO PAULO

FACULDADE DE DIREITO

SÃO PAULO / SP 


\title{
DA EXPANSÃO DOS DANOS INDENIZÁVEIS E SUA CATEGORIZAÇÃO
}

\begin{abstract}
Dissertação apresentada à Banca Examinadora do Programa de Pós-Graduação em Direito, da Faculdade de Direito da Universidade de São Paulo, como exigência parcial para obtenção do título de Mestre, com aérea de concentração em Direito Civil, sob a orientação da Professora Titular Silmara Juny de Abreu Chinellato.
\end{abstract}

UNIVERSIDADE DE SÃO PAULO

FACULDADE DE DIREITO

SÃO PAULO / SP 
Agradeço a Deus, primeira e especialmente, por me permitir esta oportunidade e, até aqui, haver me conduzido.

Aos meus pais, pelas bases firmadas e pelos constantes conselhos e direções.

À minha esposa, pelo permanente apoio e incentivo.

À Professora Silmara Chinellato, pela confiança em mim depositada, bem como pela orientação e ensinos repassados.

Aos meus professores, que sempre me abriram os horizontes, por meio do conhecimento.

Aos colegas da Pós-Graduação, pela ajuda, ideias e materiais compartilhados. 
SCRAMIM, Umberto Cassiano Garcia. Da expansão dos danos indenizáveis e sua categorização. Dissertação (mestrado). Faculdade de Direito, Universidade de São Paulo. São Paulo, 2016.

\section{RESUMO}

O presente trabalho trata da expansão de danos indenizáveis e sua classificação. Por meio de uma análise do panorama atual da responsabilidade civil, serão verificados o fenômeno da expansão de danos indenizáveis, a necessidade do dano para que exista a responsabilidade civil, o conceito de dano, sua bipartição em dano-evento e dano-prejuízo, a classificação econômica do dano (patrimoniais e não patrimoniais) e as modalidades de dano já existentes no Brasil. A partir desse exame, demonstrar-seá que sob a classificação econômica do dano, que deve ser realizada tomando por base o dano-prejuízo, somente existem duas espécies de prejuízos possíveis: os patrimoniais e os extrapatrimoniais, inexistindo uma terceira espécie diversa, que com estes possa figurar cumulativamente. Serão analisados, por fim, os prejuízos decorrentes de lesão à integridade física, dentre os quais, no sistema jurídico brasileiro, encontram-se o dano estético e o dano existencial, e examinados os danos de privação de uso e a perda de uma chance, expondo-se que não se trata de "novos danos" autônomos.

PALAVRAS-CHAVE: Responsabilidade Civil - "Novos danos" - Classificação Econômica - Dano Patrimonial - Dano Extrapatrimonial 
SCRAMIM, Umberto Cassiano Garcia. The expansion of the recoverable damages and their categorization. Dissertation (Degree Master). Faculty of Law, University of São Paulo. São Paulo, 2016.

\begin{abstract}
This work concerns about the expansion of the recoverable damages and their classification. Through an analysis of the current situation of civil liability, will be checked the phenomenon of expansion of compensable damages, the need of the damage so that subsist liability, the concept of damage, its division into damage-event and damage-prejudice, the economic classification of the damage (patrimonial and moral damage) and the kinds of damages existing in Brazil. From that examination, it will prove that under the economic classification of the damage, which must be based on the damage-prejudice, there are only two kinds of possible damages: the patrimonial and moral damages, and does not exist a third different type, that with these can figure cumulatively. Will be examined, finally, damages from injuries to physical integrity, among them, in the brazilian legal system, are aesthetic damage and existential damage, and examined the loss of use and the loss of chance, exposing that it is not "new autonomous damages".
\end{abstract}

KEYWORDS: Civil Liability - "New Damages" - Economic Classification - Patrimonial Damage - Moral Damage 
1 INTRODUÇÃO

2 PANORAMA ATUAL DA RESPONSABILIDADE CIVIL ...................................11

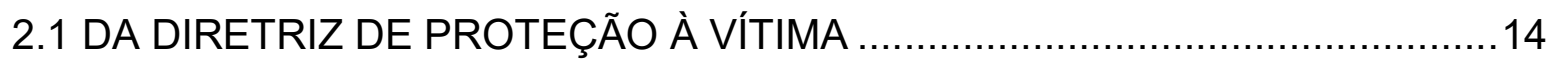

2.2 DA OBJETIVAÇÃO DA RESPONSABILIDADE CIVIL ...............................18

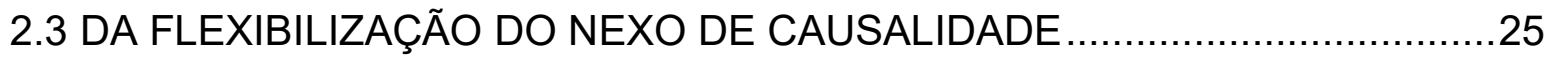

2.4 DA CRESCENTE SOCIALIZAÇÃO DOS RISCOS ………….........................

2.5. DA EXPANSÃO DOS DANOS INDENIZÁVEIS ............................................

2.5.1 Da Ampliação das Atividades Humanas Potencialmente Danosas.....45

2.5.2 Dos Novos Sujeitos de Direito............................................................51

3 DO CONCEITO DE DANO E SUA CLASSIFICAÇÃO ECONÔMICA ......................56

3.1 DO DANO COMO REQUISITO DA RESPONSABILIDADE CIVIL...................56

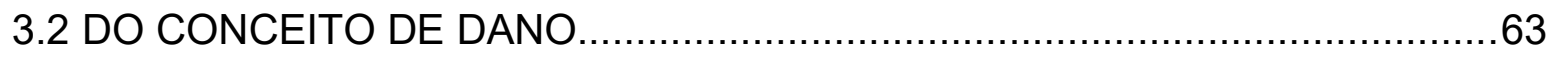

3.2.1 Da Acepção Naturalística.......................................................................63

3.2.2 Da Concepção Jurídica de Dano ...........................................................64

3.2.3 Do Dano-Evento e do Dano-Prejuízo......................................................69

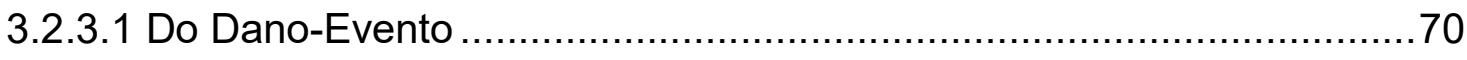

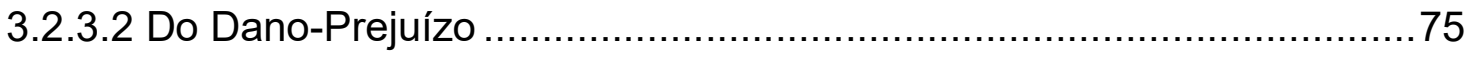

3.2.3.3 Da Inexistência de Necessária Identidade entre a Natureza do Dano-

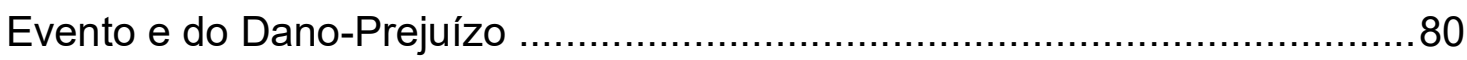

3.3 DA CLASSIFICAÇÃO ECONÔMICA DO DANO ….......................................

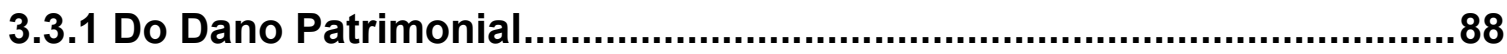

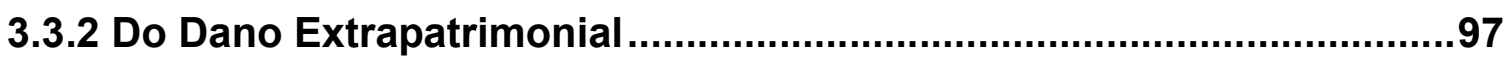

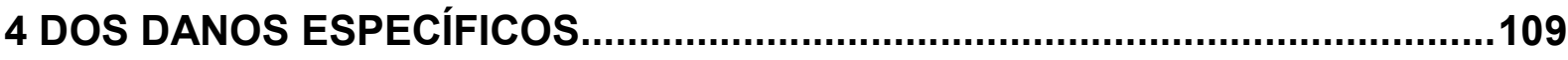


4.1 DOS DANOS À INTEGRIDADE FÍSICA (DANOS CORPORAIS OU DANOS À

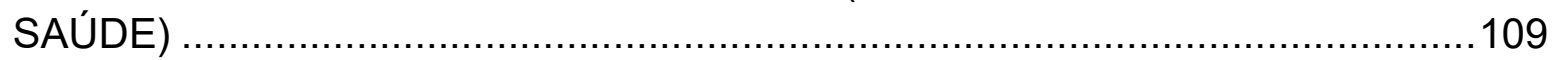

4.1.1 Do Dano Corporal no Direito Francês (Dommages Coporels)...........115

4.1.2 Do Dano à Saúde no Direito Italiano ....................................................124

4.1.3 Da Lesão à Integridade Física no Direito Brasileiro ...........................126

4.1.3.1 Dos Danos Patrimoniais ...........................................................127

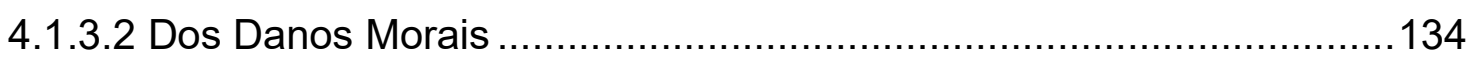

4.1.3.3 Do Dano Estético ..................................................................140

4.1.3.4 Do Dano Existencial .............................................................148

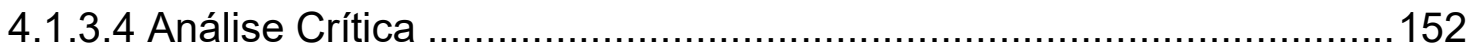

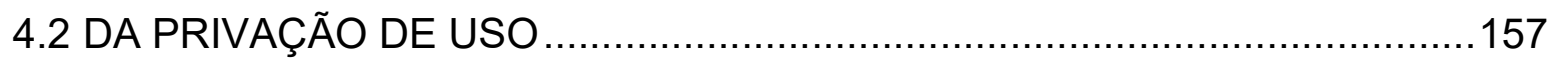

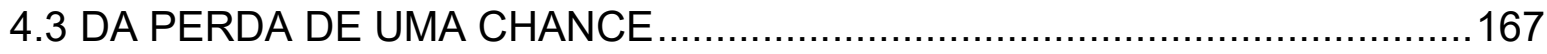

5 CONCLUSÃO

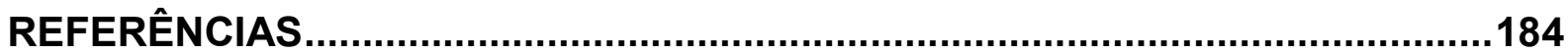




\section{INTRODUÇÃO}

Nos dias atuais, acha-se a responsabilidade civil inserida num cenário de grandes incertezas. Os novos inventos, maquinários e tecnologias, o maior contato entre as pessoas, proporcionado pelos mais variados meios, e uma forte tendência à ampliação de direitos reconhecidos têm ocasionado inúmeras e inéditas possibilidades de interferência na esfera jurídica alheia.

Ao mesmo tempo em que se estenderam imensamente as possibilidades de produção de lesões, surgiu, como contraponto a essa evolução, uma pujante inclinação no sentido de se proteger, do modo mais integral possível, a pessoa da vítima, visando torná-la indene em relação aos diversos prejuízos que se afiguravam a cada instante.

A responsabilidade civil, diante desse contexto, sofreu uma série de alterações, que tiveram origem especialmente nos entendimentos doutrinários e jurisprudenciais, posteriormente incorporados, como regra, nas legislações vigentes. Houve inúmeras flexibilizações nos requisitos necessários à imputação do dever de indenizar, cujo fim orientava-se na direção de facilitar o devido ressarcimento daquele que foi ofendido, já que os danos deixaram de ser considerados obra do acaso, para passarem a ser vistos como resultado provável do convívio social.

Essa menor rigidez na avaliação das exigências para a responsabilização, a amplificação das atividades humanas promotoras de risco, a crescente propagação dos seguros compulsórios, o reconhecimento de novos sujeitos de direito e status do ser humano, a promoção ao amplo acesso à Justiça, tudo somado ao elastecimento dos interesses juridicamente tutelados, oportunizaram a expansão dos danos indenizáveis, com a correspondente aparição de variadas espécies de prejuízos.

No Brasil, vislumbrou-se tal movimento de dilatação notadamente em momento posterior à Constituição Federal de 1988, pois, com amparo em seu texto, albergou-se a ampla possibilidade de indenizações por danos morais em nosso sistema jurídico, outrora legislativamente restrito a algumas hipóteses especificadas no Código Civil de 1916 e em leis esparsas, embora a jurisprudência já houvesse reconhecido, timidamente, a possibilidade da indenização por danos não patrimoniais em relação a diversas situações não normatizadas. 
O caminho trilhado a partir das disposições constitucionais alargou exponencialmente o reconhecimento de novos formatos de dano, para além dos danos morais já consolidados, a exemplo dos danos estéticos e dos chamados danos existenciais.

A noção do conceito de dano e respectivas classificações, então, passaram a experimentar certa instabilidade, porquanto se levantou um sem-número de novos conceitos e modalidades, cada qual se atentando a alguma especificidade deste requisito da responsabilidade.

Com os olhos voltados para essa realidade, serão analisadas neste trabalho as seguintes questões:

1. Panorama atual da responsabilidade civil e possíveis tendências;

2. O fenômeno da expansão dos danos indenizáveis;

3. A imprescindibilidade do dano para existência da responsabilidade civil;

4. O conceito de dano;

5. A bipartição do dano em dano-evento e dano-prejuízo;

6. A classificação econômica do dano (patrimoniais e extrapatrimoniais);

7. As modalidades de dano já tratadas no Brasil.

Baseando-se na verificação dos indigitados itens, procurar-se-á evidenciar, por meio de análise do tratamento doutrinário, legislativo e jurisprudencial conferido, que:

1. O panorama atual da responsabilidade civil, conjugado a outras circunstâncias, contribuiu para a expansão dos danos indenizáveis;

2. Esse fenômeno ampliativo redundou na aparição de conceitos e classificações equivocadas, mormente no que diz respeito aos prejuízos extrapatrimoniais, em que se permitiu, até mesmo, a cumulação da indenização por danos que, apresentados como autônomos, possuem a mesma natureza, proporcionando o surgimento de indesejado bis in idem;

3. O dano deve ser examinado em dois momentos, um imediato, denominado dano-evento, e outro mediato, designado dano-prejuízo, e que, a partir do segundo (consequências refletidas sobre a esfera jurídica da vítima), poder-se-á classificar o 
prejuízo, economicamente, em duas espécies: patrimoniais (subdivididos em danos emergentes e lucros cessantes) e extrapatrimoniais.

A presente pesquisa, desse modo, tem por objetivo demonstrar:

1. Que a classificação econômica do dano tem por base o dano-prejuízo, ou seja, leva em consideração a natureza dos efeitos incidentes sobre a vítima, resultantes da lesão ao interesse juridicamente tutelado (e respectiva norma de proteção);

2. Que somente existem, sob a apreciação econômica, duas espécies de prejuízo: os patrimoniais (subdivididos em danos emergentes e lucros cessantes) e os extrapatrimoniais (designados, majoritariamente, na cultura jurídica brasileira, danos morais), inexistindo um tertium genus que com eles possa se cumular;

3. Que no Brasil não se revela necessário a multipartição do dano extrapatrimonial em diversas subcategorias.

Dentro dessa perspectiva, o trabalho estruturar-se-á em três principais capítulos.

No primeiro, será analisado o panorama geral da responsabilidade civil atualmente, abordando-se a diretriz de proteção à vítima como vetor da matéria, as tendências deste ramo do direito (mitigação da culpa, flexibilização do nexo de causalidade, coletivização dos riscos e expansão dos danos indenizáveis) e como as três primeiras inclinações, associadas a outros fatores, contribuíram para a ampliação dos danos indenizáveis.

No segundo capítulo, serão verificados a imprescindibilidade da existência do dano para que ocorra o surgimento da responsabilidade civil; o conceito de dano, em sua acepção naturalística e concepção jurídica; os dois momentos em que se subdivide o dano: dano-evento e dano-prejuízo, bem como as diferenciações e consequências decorrentes desta divisão, e, por fim; a classificação econômica do dano, em que serão conceituados os danos patrimonial e extrapatrimonial.

No terceiro capítulo, examinar-se-ão resumidamente as espécies de danos já reconhecidas no sistema jurídico brasileiro, conferindo-se especial atenção aos prejuízos decorrentes de lesões à integridade física, em razão do portentoso potencial de possíveis consequências negativas oriundas da violação deste direito da 
personalidade. Será realizada, igualmente, uma breve análise dos danos corporais no direito francês e uma singela remissão aos danos biológicos (ou à saúde) ligados ao direito italiano.

Ao final, serão apresentadas as conclusões obtidas com a pesquisa realizada. 


\section{CONCLUSÃO}

Realizado o exame, no primeiro capítulo, das tendências da responsabilidade civil, com especial foco na expansão dos danos indenizáveis; na segunda seção, a verificação do conceito de dano, sua bipartição entre dano-evento e dano-prejuízo e, partindo deste último, a classificação econômica dos prejuízos, e, por fim; no terceiro capítulo, a análise dos danos já inseridos em nosso sistema jurídico; podem-se apresentar as seguintes conclusões:

1. A proteção às vítimas tem sido a grande diretriz norteadora da responsabilidade civil. Trata-se de um contraponto necessário à maior exposição à possibilidade de se sofrer danos, decorrente da evolução industrial, tecnológica e da aproximação das pessoas, que resultou na constatação de que, dentro desse contexto, os danos não são infortúnios aleatórios, mas consequências da vida em sociedade.

2. Com base nessa diretriz de proteção, consolidam-se as tendências da responsabilidade civil, que consistem: $2.1 \mathrm{Na}$ objetivação, em que se mitigou a necessidade da aferição da culpa; $2.2 \mathrm{Na}$ flexibilização do nexo de causalidade, ora adotando-se a teoria que melhor se adapte ao caso concreto e que estabeleça a relação de causalidade (inexistência de uma doutrina universalmente aceita, mas possíveis doutrinas a serem escolhidas a posteriori), ora suavizando ou mesmo afastando as excludentes do nexo causal, ora perfilhando presunções em favor da vítima; $2.3 \mathrm{Na}$ socialização dos riscos, por meio da crescente securitização compulsória, dentro de certos limites a serem estabelecidos (principalmente não abranger danos extrapatrimoniais e garantir, apenas, o necessário à subsistência digna da vítima), e; $2.4 \mathrm{Na}$ expansão de danos indenizáveis.

3. A expansão de danos indenizáveis não possui uma causa única, mas diversos fatores que se entrelaçam e proporcionam este fenômeno, dentre os quais se destacam: 3.1 A ampliação das atividades humanas potencialmente danosas, pois, com o desenvolvimento industrial e tecnológico, aumentaram-se as fontes produtoras de danos e criaram-se novas formas de se produzirem antigas lesões, de modo muito mais superlativo; 3.2 A crescente proteção jurídica aos mais diversos interesses, notadamente os de ordem não econômica; $3.3 \mathrm{~A}$ extensão de direitos a outros entes 
diversos do ser humano individualmente considerado, bem como a segmentação da pessoa em diversos status com a respectiva proteção; 3.4 A flexibilização dos demais requisitos da responsabilidade civil, que oportunizou a maior apreciação do dano, pois em diversas hipóteses nas quais a imputação do dever de indenizar já seria pela ausência de nexo causal ou culpa excluída, agora, devido à sua limitação, permite-se a verificação da efetiva existência de dano; 3.5 O maior acesso à Justiça, com a estruturação de órgãos que permitiram a participação de setores da sociedade outrora preteridos, cuja ampliação ocasionou o aumento significativo das demandas indenizatórias.

4. Em razão da alteração do foco de interesse, que do agente causador (culpa) passou à vítima (dano), o dano apresenta-se como o principal requisito da responsabilidade civil. Sem que esteja presente, não se manifestará este segmento do direito civil, que está vocacionado à indenização. As funções punitiva e preventiva somente existem de modo acessório e complementar à função reparatória, mas jamais de modo principal e isolado.

5. No ordenamento jurídico, em seus mais variados ramos (direito ambiental, consumidor, etc.), existem diversas normas objetivando a proteção de direitos, cuja finalidade é evitar a ocorrência de danos, em verdadeira manifestação dos princípios da prevenção e da precaução. A ameaça de violação a essas normas, que possivelmente resultará em dano, deverá ser combatida por instrumentos processuais, denominados tutela inibitória e tutela de remoção do ilícito. Tais mecanismos não pertencem à responsabilidade civil, que, por possuir finalidade de conferir indenização àquele que sofreu prejuízo, apenas dará ensejo ao surgimento da tutela específica ressarcitória ou do equivalente em pecúnia.

6. Nem todo dano resultará no dever de indenizar, mas somente aquele cujo interesse violado seja objeto de proteção normativa e o dever de reparação possa ser imputado a terceira pessoa. Não interessa ao direito a acepção naturalística do termo dano, no sentido de perda ou diminuição de uma situação de vantagem, mas somente a noção jurídica.

7. O conceito de dano está relacionado à ideia de lesão a um interesse e não a determinado bem. Os bens são entidades com o potencial de satisfazer carências. Estas, por sua vez, são exigências decorrentes da falta de algo, que fomentam a busca do bem que possua potencial específico para atendimento de determinada 
ausência. Já os interesses são a ligação entre certa carência e determinado bem, consistindo na própria satisfação das exigências. Os sujeitos de direito, por possuírem infindáveis carências cujos bens são capazes de satisfazer, estão ligados a incontáveis interesses. A noção jurídica de dano, então, pode ser sintetizada como a lesão a um interesse juridicamente tutelado, que produza consequências que serão objeto de reparação ou compensação.

8. A configuração do dano se biparte em dois momentos, um imediato, referente à violação de um interesse juridicamente tutelado (e, por via de consequência, da própria norma), denominado dano-evento, e outro mediato, atinente às consequências negativas advindas da lesão realizada, chamado dano-prejuízo. Ambos são indispensáveis ao surgimento do dano indenizável.

9. O dano-evento está ligado à violação de alguma norma, visto que, ao lesar o interesse protegido, automaticamente atingirá a norma que o protege. A antijuridicidade neste caso é aferida em relação ao resultado e não à conduta, já que se procura identificar se o interesse da vítima afetado é ou não objeto de tutela jurídica. Haverá, assim, condutas lícitas que gerarão resultados ilícitos - isto é, produzirão dano-evento, e condutas ilícitas que não atingirão interesses alheios juridicamente protegidos - ou seja, não produzirão dano-evento. A ilicitude, no ponto, somente será verificada em seu aspecto objetivo, em relação à contrariedade ao direito, que poderá ser um direito subjetivo ou uma norma de proteção a interesses alheios (geralmente ligadas à tutela da Administração Pública ou de interesses coletivos).

10. O dano-prejuízo consiste nos efeitos decorrentes da lesão ao interesse juridicamente protegido (dano-evento), na análise concreta de que se naquele caso específico a violação do direito redundou em efeitos negativos à esfera jurídica da vítima. Tanto a identificação da natureza da indenização, se patrimonial ou extrapatrimonial, como sua extensão (quantificação) estão adstritas ao dano-prejuízo. A análise deste envolve três aspectos principais: 1. A verificação da existência concreta de prejuízos; 2. O exame da natureza desses prejuízos; 3. A quantificação da indenização.

11. Nem sempre a ocorrência de um dano-evento, que é verificado objetivamente, resultará na aparição do dano-prejuízo, embora esta seja a regra. Nem mesmo nos casos de lesão a direitos da personalidade (dano-evento) haverá, automaticamente, o surgimento do dano-prejuízo. Há, nestes casos, uma presunção 
de que a violação destes direitos causará prejuízos à vítima, dispensando-se, assim, outra prova acerca das consequências negativas, já que se trata do que ordinariamente acontece. Mas hipóteses haverá em que, conquanto exista uma violação a direito da personalidade, inexistirá prejuízos, não subsistindo a indigitada presunção, em razão das circunstâncias do caso concreto.

12. Não existe uma correlação necessária entre a natureza do dano-evento e a do dano-prejuízo. Embora comumente possuam identidade de caráter, não se está diante de uma regra absoluta, porquanto a violação de direitos patrimoniais poderá dar ensejo ao surgimento de danos morais, associados ou não com os danos materiais, e a lesão a direitos da personalidade poderá ocasionar a aparição de danos patrimoniais, conjugados ou não aos danos morais.

13. Dentre as diversas classificações possíveis do dano, cada qual estruturada sobre um ou outro aspecto deste, revela-se como a mais importante aquela em que, como critério de distinção, atenta para a economicidade do prejuízo efetivamente sofrido pela vítima (dano-prejuízo), cujas espécies são denominadas dano patrimonial (ou material) e dano extrapatrimonial (ou moral). No caso, não se analisa a natureza do direito violado ou mesmo a do bem lesionado, mas qual o setor da esfera jurídica da vítima foi prejudicado, se aquele cujo conteúdo é econômico ou não econômico (ou ambos).

14. Desse modo, a melhor conceituação do dano moral é aquela que se vale do critério negativo, ou seja, da ausência de economicidade do prejuízo. Conceitos substantivos mostram-se inconsistentes, pois: 1. Ou confundem os momentos do dano, trocando o dano-prejuízo pelo dano-evento, como ocorre quando se conceitua o dano moral como lesão a direito da personalidade ou à dignidade humana, visto que a lesão a tais direitos constitui o dano-evento, que pode resultar tanto em danos patrimoniais, como em danos morais propriamente ditos; 2 . Ou não abrangem todas as possíveis consequências não econômicas, limitando indevidamente sua extensão; 3. Ou não tutelará todas as possíveis vítimas. Dano extrapatrimonial, então, pode ser conceituado como o prejuízo não patrimonial decorrente de uma lesão a interesse juridicamente tutelado.

15. Sob aspecto econômico, os danos-prejuízo somente assumirão duas únicas feições: uma de índole patrimonial (denominado "dano patrimonial”) e outra de índole não patrimonial (designado "dano extrapatrimonial). Inexiste hipótese outra de 
prejuízo autônomo, paralelo aos acima mencionados, que com eles possa figurar conjuntamente. Qualquer outra espécie que se apresente, necessariamente, se subsumirá a uma das duas hipóteses, porquanto as utilidades frustradas somente podem ser econômicas ou não.

16. Os maiores dilemas relacionam-se aos danos extrapatrimoniais, pois enquanto os danos patrimoniais possuem efeitos específicos (perda de valores e frustração de lucro), cujos limites são mais bem estabelecidos (em razão de sua possível aferição matemática), inúmeras são as possíveis consequências não patrimoniais de um dano-evento, especialmente quando se está diante de uma lesão à integridade física.

17. O fato de um dano-evento poder gerar diversos efeitos não econômicos não permite que cada prejuízo transforme-se numa nova categoria de dano: 1 . Seja por se revelar inadequada tal postura, já que não se pode distinguir exatamente onde começa e onde termina cada espécie de prejuízo não patrimonial, dada a inexistência de limites aritméticos; 2. Seja por se mostrar desnecessário tal procedimento, pois há ampla abertura aos danos morais no ordenamento brasileiro, devendo a indenização por danos extrapatrimoniais levar em consideração a maior ou menor extensão dos efeitos da lesão, e assim ser arbitrada segundo a respectiva amplitude.

18. A questão restringe-se à adequada quantificação da indenização e não se deve, para atingir esse fim, realizar a criação de um sem-número de "novos" prejuízos, com indenizações autônomas, pois: 1. A lista tenderia ao infinito (devido à abertura ao dano moral e aos direitos da personalidade); 2. Não permitiria a correta distinção entre as modalidades (acarretando inevitável bis in idem), e; 3. Não garantiria que o montante da indenização fosse consentâneo à situação (se se arbitrar valores módicos aos diversos prejuízos etiquetados, a indenização permanecerá insuficiente à devida compensação). Não se atingirá a integral compensação da vítima com a criação de uma nova nomenclatura para cada prejuízo imaginável. A indenização por danos extrapatrimoniais deve ser estipulada de modo unitário e não multipartida em infindáveis categorias. Sua correta e suficiente fixação exige que se leve em consideração as nuanças do caso, com o fim de se realizar a necessária aferição da extensão das consequências e, assim, arbitrar-se a devida compensação.

19. No Brasil, segundo consolidada jurisprudência, é possível a cumulação de indenizações por dano material, moral e estético. Há, também, o surgimento de uma 
nova modalidade de dano, denominada "dano existencial", já acolhida por alguns julgados prolatados por tribunais trabalhistas. Em ambos os casos, revela-se equivocado elevar os mencionados danos a categorias autônomas, de modo a figurarem ao lado dos danos patrimoniais e extrapatrimoniais.

20. Com relação ao dano estético, impende destacar que este consiste numa característica, numa peculiaridade da lesão à integridade física, fazendo parte do dano-evento. Quando estiver presente, poderá resultar em danos-prejuízo patrimoniais ou extrapatrimoniais.

21. No que tange ao dano existencial, cumpre esclarecer que não se trata de uma nova espécie de dano. Seu conteúdo abrange diversos prejuízos não econômicos decorrentes de lesão à higidez psicofísica, que refletem cerceamentos ocasionados à vítima, com consequências prejudiciais sobre as possibilidades atuais ou vindouras. Ou seja, em substância, tratam-se dos próprios danos extrapatrimoniais.

22. O chamado dano de privação de uso refere-se aos prejuízos oriundos da indisponibilização temporária da utilização de determinado bem. Trata-se de complexa questão debatida no direito português e que também já se acha em apreciação no Brasil, por meio de diversos julgados, embora não sob esta nomenclatura. Importa explicitar que não se trata de nova modalidade, alheia aos danos material e moral, mas sim de parte do dano-evento (violação temporária do direito de propriedade), que produzirá dano-prejuízo de natureza patrimonial e, possivelmente, e de modo excepcional, danos extrapatrimoniais.

23. Com relação à perda de uma chance, embora reflita a tendência de expansão de danos indenizáveis, não constitui uma nova modalidade de dano, estranha aos prejuízos patrimoniais e extrapatrimoniais. Trata-se, antes, de uma técnica de deslocamento do objeto de reparação, em que se deixa de analisar o dano final (vantagem realmente pretendida), para se avaliar o momento antecedente, referente à própria chance de se atingir a vantagem final. Nos casos da denominada perda de uma chance "atípica", em que o processo aleatório não é interrompido, resultando na frustração da chance de se evitar um prejuízo, a questão, segundo parte da doutrina, estaria ligada a um problema de nexo de causalidade. De um modo ou de outro, quando a chance que se apresenta real e séria restar frustrada, poderá produzir prejuízos de natureza patrimonial ou extrapatrimonial (ou ambos), a depender 
dos reflexos do dano na esfera pessoal da vítima, levando-se em consideração, como critério de identificação, a natureza da vantagem final perseguida pela vítima. 


\section{REFERÊNCIAS}

AGOGLIA, María Martha. El daño jurídico: enfoque actual. Buenos Aires: La Ley, 2000.

ALMEIDA, José Luiz Gavião de. Responsabilidade sem dano no Código Civil de 2002. Tese apresentada no concurso para Professor Titular do Departamento de Direito Civil da Faculdade de Direito da Universidade de São Paulo, 2011.

ALMEIDA, Silmara Juny Abreu Chinellato. Tutela civil do nascituro. São Paulo: Saraiva, 2000.

ALPA, Guido. I/ danno biológico: percorso di um'idea. $3^{a}$ ed. Padova: CEDAM, 2003.

ALVES, José Carlos Moreira. Direito romano. 16ª ed. Rio de Janeiro: Forense, 2014.

ALVIM, Agostinho. Da inexecução das obrigações e suas consequências. $5^{\mathrm{a}}$ ed. São Paulo: Saraiva, 1980.

ALVIM, Pedro. O Contrato de seguro. $3^{\text {a }}$ ed. Rio de Janeiro: Forense, 1999.

AZEVEDO, Antonio Junqueira de. Cadastro de restrição ao crédito. Conceito de dano moral. In: Estudos e pareceres de direito privado. São Paulo: Saraiva, 2004.

. O direito como sistema complexo e de $2^{\mathrm{a}}$ ordem; sua autonomia. Ato nulo e ato ilícito. Diferença de espírito entre responsabilidade civil e penal. Necessidade de prejuízo para haver direito de indenização na responsabilidade civil. In: Estudos e pareceres de direito privado. São Paulo: Saraiva, 2004.

BASTOS, Celso Ribeiro. Curso de direito constitucional. 19ª ed. São Paulo: Saraiva, 1998.

BAUMAN, Zygmunt. Danos colaterais: desigualdades sociais numa era global. Tradução de Carlos Alberto Medeiros. Rio de Janeiro: Zahar, 2013.

Modernidade líquida. Tradução de: Plínio Dentzien. Rio de Janeiro: Zahar,

2001. 
BECK, Ulrich. Sociedade de risco: rumo a outra modernidade. Tradução de: Sebastião Nascimento. 2a ed. São Paulo: Editora 34, 2011.

BENJAMIN, Antonio Herman V. Responsabilidade civil pelo dano ambiental. In: Revista de Direito Ambiental. vol. 9. p. 5-52, 1998.

BEVILÁQUA, Clóvis. Código civil comentado. vol. 1. 11 $1^{\mathrm{a}}$ ed. Rio de Janeiro: Livraria Francisco Alves, 1956.

BIANCA, C. MASSIMO. Diritto civile: la responsabilità. vol. 5. Milano: Giuffrè, 1994.

BITTAR, Carlos Alberto. Curso de direito civil. Vol. 1. Rio de Janeiro: Forense Universitária, 1994.

. Os direitos da personalidade. $4^{\mathrm{a}}$ ed. Rio de Janeiro: Forense Universitária, 2000.

1997.

. Reparação civil por danos morais. $3^{a}$ ed. São Paulo: Revista dos Tribunais, . . Responsabilidade civil nas atividades nucleares. São Paulo: Revista dos Tribunais, 1985.

BOBBIO, Norberto. A era dos direitos. Tradução de: Carlos Nelson Coutinho. Rio de Janeiro: Elsevier, 2004.

BONAVIDES, Paulo. Curso de direito constitucional. 25a ed. São Paulo: Malheiros, 2010.

BREBBIA, Roberto H. El daño moral. 2ª ed. Cordoba: ORBIR, 1967.

CAHALI, Yussef Said. Dano moral. 4ª ed. São Paulo: Revista dos Tribunais, 2011.

CAPELO DE SOUSA, Rabindranath Valentino Aleixo. $O$ direito geral de personalidade. Coimbra: Coimbra Editora, 2011. 
CANOTILHO, José Joaquim Gomes. Direito constitucional e teoria da constituição. 4. ed. Coimbra: Almedina, 2001.

CARNAÚBA, Daniel Amaral. A responsabilidade civil pela perda de uma chance: a técnica na jurisprudência francesa. In: Doutrinas essenciais de dano moral. Vol. 1/2015. p. 1285-1315. São Paulo: Revista dos Tribunais, Julho, 2015.

Responsabilidade civil pela perda de uma chance: a álea e a técnica. Rio de Janeiro: Forense, 2013.

CARNELUTTI, Francesco. Teoria geral do direito. Tradução de: Antônio Carlos Ferreira. São Paulo: LEJUS, 1999.

CASTRONOVO, Carlo. Danno biológico: un itinerario di diritto giurisprudenziale. Milano: Giuffrè, 1998.

CAVALIERI FILHO, Sérgio. Programa de responsabilidade civil. $11^{a}$ ed. São Paulo: Malheiros, 2014.

CHAVES, Antonio. Tratado de direito civil. v. 1. São Paulo: Revista dos Tribunais, 1982.

CHINELLATO, Silmara Juny de Abreu. Adoção de nascituro e a quarta era dos direitos: razões para se alterar o caput do art. 1.621 do novo código civil. In: DELGADO, Mário Luiz; ALVES, Jones Figueirêdo. Novo código civil: questões controvertidas. São Paulo: Método, 2003.

. Comentários à parte Geral - artigos $1^{\circ}$ a 21 do código civil. In: MACHADO, Antonio Cláudio da Costa (Org.). CHINELLATO, Silmara Juny de Abreu (Coord.). Código civil interpretado artigo por artigo, parágrafo por parágrafo. $6^{a}$ ed. São Paulo: Manole, 2013.

. Da responsabilidade civil no código de 2002 - aspectos fundamentais. Tendências do direito contemporâneo. In: TEPEDINO, Gustavo; FACHIN, Luiz Edson. (Org.). O direito e o tempo: embates jurídicos e utopias contemporâneas. Estudos em homenagem ao Professor Ricardo Pereira Lira. Rio de Janeiro: Renovar, 2008.

. Obras póstumas e direito e autor. In: SIMÃO, José Fernando; BELTRÃO, Silvio Romero (Coord.). Direito civil: estudos em homenagem a José de Oliveira Ascensão. vol. 1. São Paulo: Atlas, 2015. 
Pessoa natural e novas tecnologias. Revista do Instituto dos Advogados de São Paulo, vol. 27, janeiro, 2011.

. Tendências da responsabilidade civil no direito contemporâneo: Reflexos no código civil de 2002. In: DELGADO, Mário Luiz; ALVES, Jonas Figueirêdo. Novo código civil: questões controvertidas. São Paulo: Método, 2006.

CLOTET, Joaquim. Bioética: uma aproximação. Porto Alegre: EdiPUCRS, 2003.

CONSELHO DE ESTADO DA FRANÇA. Responsabilidade e socialização do risco. Tradução: Michel Abes. Coord. Marcelo Dias Varella. Brasília: UNICEUB, 2006.

CONTI, José Mauricio. Direito do consumidor: indenização por veículo parado em concessionária. Revista do Advogado. n. 49, p. 47-54, dez/1996.

CORDEIRO, António Menezes. Tratado de direito civil. Parte geral. Coisas. vol. 3. $3^{a}$ ed. Coimbra: Almedina, 2013.

Tratado de Direito Civil. Gestão de negócios. Enriquecimento sem causa. Responsabilidade civil. vol. 8. Coimbra: Almedina, 2014.

CRUZ, Gisela Sampaio da. O problema do nexo causal na responsabilidade civil. Rio de Janeiro: Renovar, 2005.

DE CUPIS, Adriano. II danno: teoria generale della responsabilità civile. vol 1. $2^{\mathrm{a}}$ ed. Milano: Giuffrè, 1966.

. Os direitos da personalidade. Tradução de: Afonso Celso Furtado Rezende. $2^{\text {a }}$ ed. São Paulo: Quorum, 2008.

DESMOULIN-CANSELIER, Sonia. Quel droit pour lês animaux? Quel statut juridique pour l'animal? In: Revue Pouvoirs. n. ${ }^{\circ}$ 131. p. 43-56. Les animaux. Novembre, 2009. (disponível em: http://www.revue-pouvoirs.fr/Quel-droit-pour-les-animaux-Quel.html Acesso em: 31.03.2015).

DIAS, José de Aguiar. Da responsabilidade civil. $8^{\mathrm{a}}$ ed. Rio de Janeiro: Forense, 1987. 
. Dano psíquico e dano estético: uma decisão memorável. Porto Alegre: Ajuris, v. 10, Novembro, 1983..

DÍAZ, Julio Alberto. Responsabilidade coletiva. Belo Horizonte: Del Rey, 1998.

DINAMARCO, Cândido Rangel. Instituições de direito processual civil. vol. 1. $5^{\mathrm{a}}$ ed. São Paulo: Malheiros, 2004.

Instituições de direito processual civil. vol. 3. $4^{\mathrm{a}}$ ed. São Paulo: Malheiros,

2002.

DINTILHAC, Jean-Pierre. Rapport du groupe de travail chargé d'elaborer une nomenclature des préjudices corporels. Paris: Ministère de la Justice, Juillet/2005.

FABRE-MAGNAN, Muriel. Droit des obligations. Responsabilité civile et quasicontrats. $3^{a}$ édition. Paris: PUF, 2013.

FISCHER, Hans Albrecht. A reparação dos danos no direito civil. Tradução de: António de Arruda Ferrer Correia. São Paulo: Académica, 1938.

GERALDES, António Santos Abrantes. Temas da responsabilidade civil: indeminização do dano da privação de uso. vol. 1. $3^{a}$ ed. Coimbra: Almedina, 2007.

GHERSI, Carlos Alberto. Derecho y reparación de daños: daño a la persona humana em sus derechos a la personalidad e integridad. vol. 5. Buenos Aires: Universidad, 2005.

GOMES, Júlio Manuel Vieira. Anotações: Custo das reparações, valor venal ou valor de substituição? - Ac. do STJ de 27.02.2003 Rev. 4016/02. In: Cadernos de Direito Privado, N. ${ }^{\circ}$ 3. Julho / Setembro, 2003.

GOMES, Orlando. Obrigações. 9ª ed. Rio de Janeiro: Forense, 1994.

GONÇALVES, Carlos Roberto. Comentários ao código civil - parte especial: direito das obrigações. vol. 11 (arts. 927 a 965). Coord. Antônio Junqueira de Azevedo. São Paulo: Saraiva, 2003. 
GUEDES, Gisela Sampaio da Cruz. Lucros cessantes: do bom-senso ao postulado normativo da razoabilidade. São Paulo: Revista dos Tribunais, 2011.

HIGA, Flávio da Costa. Responsabilidade civil. A perda de uma chance no direito do trabalho. São Paulo: Saraiva, 2012.

HIRONAKA, Giselda M. F. Novaes. Responsabilidade pressuposta: evolução de fundamentos e de paradigmas da responsabilidade civil na contemporaneidade. In: TEPEDINO, Gustavo; FACHIN, Luiz Edson. (Org.). O direito e o tempo: embates jurídicos e utopias contemporâneas. Estudos em homenagem ao Professor Ricardo Pereira Lira. Rio de Janeiro: Renovar, 2008.

HORBACH, Carlos Bastide. Memória jurisprudencial: Ministro Pedro Lessa. Brasília: Supremo Tribunal Federal, 2007.

ITURRASPE, Jorge Mosset. Responsabilidad de los profesionales. Santa Fé: Rubinzal - Culzoni Editores, 2001.

JOSSERAND, Louis. Del abuso de los derechos y otros ensayos. Bogotá: Editorial Temis S.A., 1999.

. Evolução da responsabilidade civil. Tradução de: Raul Lima. Revista Forense, vol. 86, p. 52 - 63, Junho, 1941.

LAMBERT-FAIVRE, Yvonne; PORCHY-SIMON, Stéphanie. Droit du dommage corporel. $7^{a}$ ed. Paris: Dalloz, 2012.

LARENZ, Karl. Derecho de obligaciones. vol. 2. Madrid: Revista de Derecho Privado, 1958.

LE TOURNEAU, Philippe; CADIET, Loïc. Droit de la responsabilité e des contrats. Paris: Dalloz, 2002/2003.

LE TOURNEAU, Philippe. La responsabilité civile. 2ª ed. Paris: Dalloz, 1976.

LEITÃO, Luís Manuel Teles Menezes. Direito das obrigações. vol. 1. 12 ${ }^{\mathrm{a}}$ ed. Coimbra: Almedina, 2015. 
LEMOS, Patrícia Faga Iglecias. Direito ambiental: responsabilidade civil e proteção ao meio ambiente. $3^{\mathrm{a}}$ ed. São Paulo: Revista dos Tribunais, 2010.

LEONARDI, Marcel. Responsabilidade civil dos provedores de serviços na internet. Belo Horizonte: Juarez de Oliveira, 2005.

LIMA, Alvino. Culpa e risco. $2^{\text {a }}$ ed. São Paulo: Revista dos Tribunais, 1998.

LIMA, Zulmira Pires de. Responsabilidade civil por danos morais. In: Revista Forense, n. ${ }^{\circ} 83$, p. 216-226, Jul-Set, 1940.

LIMONGI FRANÇA, Rubens. Direitos da personalidade: coordenadas fundamentais. In: Revista dos Tribunais. vol. 567, p. 09-16, Janeiro, 1983. Maio, 1988

Reparação do dano moral. In: Revista dos Tribunais. vol. 631, p. 29-37.

LOPEZ, Teresa Ancona. Dano existencial. Revista de Direito Privado. São Paulo: Revista dos Tribunais, vol. 57, p. 287-302, Jan - Mar / 2014.

O dano estético. $3^{\mathrm{a}}$ ed. São Paulo: Revista dos Tribunais, 2004.

Princípio da precaução e evolução da responsabilidade civil. São Paulo: Quartier Latin, 2010.

KFOURI NETO, Miguel. Culpa médica e ônus da prova. São Paulo: Revista dos Tribunais, 2002.

MANCUSO, Rodolfo de Camargo. Interesses difusos: conceito e legitimação para agir. $8^{\mathrm{a}}$ ed. São Paulo: Revista dos Tribunais, 2013.

MARINO, Francisco Paulo de Crescenzo. Perdas e danos. In: LOTUFO, Renan; GIOVANNI, Ettore Nanni. Obrigações. São Paulo: Atlas, 2011.

MARINONI, Luiz Guilherme. Técnica processual e tutela dos direitos. $4^{\mathrm{a}}$ ed. São Paulo: Revista dos Tribunais, 2013. 
MARTINS-COSTA, Judith. Os danos à pessoa no direito brasileiro e a natureza da sua reparação. In: A reconstrução do direito privado. São Paulo: Revista dos Tribunais, 2002.

MARTINEZ, Wladimir Novaes. Curso de direito previdenciário. Tomo I. São Paulo: LTr, 1998.

MARTINS, Sérgio Pinto. Direito da seguridade social. 32ª ed. São Paulo: Atlas, 2012.

MATOS, Eneas de Oliveira. Dano moral e dano estético. Rio de Janeiro: Renovar, 2008.

MELLO, Marcos Bernardes de. Teoria do fato jurídico: plano da existência. $20^{\mathrm{a}}$ ed. São Paulo: Saraiva, 2014.

MENDES, Gilmar Ferreira; BRANCO, Paulo Gustavo Gonet. Curso de direito constitucional. 9 a ed. São Paulo: Saraiva, 2014.

MESSINEO, Francesco. Manualle di diritto civile e commerciale. vol. 1. 9a ed. Milano: Giuffrè, 1957.

MIGLIORE, Alfredo Domingues Barbosa. Personalidade jurídica dos grandes primatas. Belo Horizonte: Del Rey, 2012.

MINOZZI, Alfredo. Danno non patrimonale. $2^{\mathrm{a}}$ ed. Milano: Società Editrice, 1909.

MONTEIRO, Washington de Barros; MALUF, Carlos Alberto Dabus; SILVA, Regina Beatriz Tavares da. Curso de direito civil: direito das obrigações. $2^{a}$ Parte. vol. 5. $41^{a}$ ed. São Paulo: Saraiva, 2014.

MORAES, Maria Celina Bodin de. Na medida da pessoa humana: estudos de direito civil-constitucional. Rio de Janeiro: Renovar, 2010.

MORATO, Antonio Carlos. Dano à imagem. In: JUNIOR, Otavio Luiz Rodrigues; MAMEDE, Gladston; ROCHA, Maria Vital da. Responsabilidade civil contemporânea: em homenagem a Sílvio de Salvo Venosa. São Paulo: Atlas, 2011. 
MORSELLO, Marco Fábio. A responsabilidade civil e a socialização dos riscos. O sistema neozelandês e a experiência escandinava. In: Revista da Escola Paulista da Magistratura. Ano 7, n. ${ }^{\circ}$ 2, p. 13-22, julho-dezembro, 2006.

. O nexo causal e suas distintas teorias: apreciações críticas. In: Revista do Instituto dos Advogados de São Paulo. vol. 19. Jan-Jun, 2007.

NORONHA, Fernando. Direito das obrigações. 4ª ed. São Paulo: Saraiva, 2013.

. O nexo de causalidade na responsabilidade civil. In: Doutrinas essenciais de responsabilidade civil. vol. 07. São Paulo: Revista dos Tribunais, 2011.

Os danos à pessoa, corporais (ou biológicos) e anímicos (ou morais em sentido estrito), e suas relações com os danos patrimoniais e extrapatrimoniais. In: Revista de Direito Privado. Vol. 22, P. 83-95, Jun / 2005

OLIVEIRA, Sebastião Geraldo de. Indenizações por acidente do trabalho ou doenças ocupacionais. $7^{\text {a }}$ ed. São Paulo: LTr, 2013.

PASSOS, J.J. Calmon de. O imoral nas indenizações por dano moral. In: LEITE, Eduardo de Oliveira. Grandes temas da atualidade - dano moral. Rio de Janeiro: Forense, 2002.

PEREIRA, Caio Mário da Silva. Direito civil: alguns aspectos de sua evolução. Rio de Janeiro: Forense, 2001.

. Instituições de direito civil. $20^{\mathrm{a}}$ ed. Rio de Janeiro: Forense, 2004.

Responsabilidade civil. 8ª ed. Rio de Janeiro: Forense, 1997.

PINTO, Paulo Mota. Interesse contratual negativo e interesse contratual positivo. Vol. 1. Coimbra: Coimbra Ed., 2008.

RIZZARDO, Arnaldo. Responsabilidade civil. 6ª ed. Rio de Janeiro: Forense, 2013.

RODOTÀ, Stefano. A Vida na sociedade da vigilância. A privacidade hoje. Tradução: Danilo Doneda e Luciana Cabral Doneda. Rio de janeiro: RENOVAR, 2008. 
RODRIGUES, Silvio. Direito civil: responsabilidade civil. vol. 4. $21^{\text {a }}$ ed. São Paulo: Saraiva, 2004.

SALEILLES, Raymond. Les accidents de travail et la responsabilité civile. Paris: L.N.D.J., 1897.

SANSEVERINO, Paulo de Tarso Vieira. Princípio da reparação integral do dano. São Paulo: Saraiva, 2010.

SANTOS. Antonio Jeová. Dano moral indenizável. $5^{a}$ ed. Salvador: Juspodivm, 2015.

SAVATIER, René. Les métamorphoses économiques et sociales du droit privé d'aujourd'hui. $3^{\text {a }}$ série. Paris: Dalloz, 1959.

SAVI, Sérgio. Responsabilidade pela perda de uma chance. $2^{\mathrm{a}}$ ed. São Paulo: Atlas, 2009.

SCHREIBER, Anderson. Novas tendências da responsabilidade civil brasileira. In: Responsabilità Civile e Previdenza, vol. 71, n. 3, Milano: Giuffrè, marzo, 2006, p. 586600. Disponível em http://www.andersonschreiber.com.br/artigos.html, acesso em 21.04.2015.

Novos paradigmas da responsabilidade civil: da erosão dos filtros da reparação à diluição dos danos. $5^{\mathrm{a}}$ ed. São Paulo: Atlas, 2013.

SEVERO, Sérgio. Os danos extrapatrimoniais. São Paulo: Saraiva, 1996.

SILVA, Clóvis Veríssimo do Couto e. O conceito de dano no direito brasileiro e comparado. In: Revista dos Tribunais. vol. 667, p. 07-16, São Paulo: Revista dos Tribunais, 1991.

SILVA, Manuel Gomes da. O dever de prestar e o dever de indemnizar. vol. 1. Lisboa, 1944.

SILVA, Rafael Peteffi. Responsabilidade civil pela perda de uma chance. $3^{\text {a }}$ ed. São Paulo: Atlas, 2013. 
SILVA, Wilson Melo da. O Dano Moral e Sua Reparação. $2^{\mathrm{a}}$ ed. Rio de Janeiro: Forense, 1969.

. Responsabilidade sem culpa e socialização do risco. Belo Horizonte: Bernardo Alvares, 1962.

SINGER, Peter. Libertação animal. São Paulo: Lugano, 2004.

SOARES, Flaviana Rampazzo. Responsabilidade civil por dano existencial. Porto Alegre: Livraria do Advogado, 2009.

STOCO, Rui. Tratado de responsabilidade civil. $10^{\mathrm{a}}$ ed. São Paulo: Revista dos Tribunais, 2014.

SUNSTEIN, Cass R.; NUSSBAUM, Martha C. Animal right - current debates and new directions. Oxford USA Trade, 2005.

TAVARES, Juarez. As controvérsias em torno dos crimes omissivos. Rio de Janeiro: ILACP, 1996.

TEPEDINO, Gustavo; BARBOZA, Heloísa Helena; MORAES, Maria Celina Bodin de. Código civil interpretado conforme a constituição da república. vol. 2. Rio de Janeiro: Renovar, 2006.

. Notas sobre o nexo de causalidade. In: Revista Trimestral de Direito Civil. vol. 6. Rio de Janeiro: PADMA, 2001.

. Seguro obrigatório de veículos e indenização por dano moral. Revista dos Tribunais Rio de Janeiro. vol. 4. p. 245-260. Mar-Abr, 2014.

THEODORO JÚNIOR, Humberto. Dano moral. $2^{\text {a }}$ ed. Belo Horizonte: Juarez de Oliveira, 1999.

. Responsabilidade civil: noções gerais. Responsabilidade objetiva e subjetiva. In: JUNIOR, Otavio Luiz Rodrigues; MAMEDE, Gladston; ROCHA, Maria Vital da. Responsabilidade civil contemporânea: em homenagem a Sílvio de Salvo Venosa. São Paulo: Atlas, 2011. 
VARELA, João de Matos Antunes. Das obrigações em geral. vol. 1. 10ª ed. Coimbra: Almedina, 2000.

VINEY, Geneviève. As tendências atuais do direito da responsabilidade civil. Tradução de: Paulo Cezar de Mello. In: TEPEDINO, Gustavo (org.). Direito civil contemporâneo: novos problemas à luz da legalidade constitucional. São Paulo: Atlas, 2008.

. Le déclin de la responsabilité individuelle. Paris: L.G.D.J. 1965.

. Traité de droit civil: introduction à la responsabilité. $3^{\mathrm{a}}$ ed. Paris: L.G.D.J.,

2008.

; JOURDAIN, Patrice; CARVAL, Suzanne. Traité de droit civil: les conditions de la responsabilité. $4^{\text {a }}$ ed. Paris: L.G.D.J., 2013.

; JOURDAIN, Patrice. Traité de droit civil: les effets de la responsabilité. $3^{\mathrm{a}}$ ed. Paris: L.G.D.J., 2010.

VISINTINI, Giovanna. Tratado de la responsabilidad civil. El daño. Otros criterios de imputación. Tradução para o espanhol de: Aída Kemelmajer de Carlucci. vol. 2. Buenos Aires: Editorial Astrea, 1999.

ZANNONI, Eduardo Antônio. El daño en la responsabilidad civil. Buenos Aires: Astrea, 1982.

ZIVIZ, Patrizia. Verso un altro paradigma risarcitorio. In: CENDON, Paolo e ZIVIZ, Patrizia. II danno existenziale. Una nuova categoria della responsabilità civile. Milano: Giuffrè, 2000. 